\title{
Pancreatic Injury Secondary to Renal Ischemia/Reperfusion (I/R) Injury: Possible Role of Oxidative Stress
}

\author{
A. M. HUSSEIN ${ }^{1}$, A. ABD-ELKHABIR ${ }^{2}$, A. ABOZAHRA ${ }^{2}$, A. BAIOMY ${ }^{3}$, \\ S. A. ASHAMALLAH ${ }^{4}$, H. A. SHEASHAA ${ }^{5}$, M. A. SOBH $^{5}$ \\ ${ }^{1}$ Medical Physiology Department, ${ }^{2}$ Mansoura Faculty of Medicine, ${ }^{3}$ Clinical Pathology Department, \\ ${ }^{4}$ Pathology Department, and ${ }^{5}$ Urology and Nephrology Center, Faculty of Medicine, Mansoura \\ University, Egypt
}

Received December 16, 2012

Accepted July 19, 2013

On-line November 1, 2013

\begin{abstract}
Summary
Recent studies demonstrated remote effects of renal ischemia/reperfusion (I/R) injury on some organs such as brain, liver, and lungs. We investigated the effects of renal I-R injury on function, histology and oxidative stress state of pancreas. Twenty -four male adult Sprague-Dawley rats were divided equally into 2 groups; sham group: rats underwent midline laparotomy and dissection of renal pedicles without renal ischemia, and ischemic group: rats underwent bilateral renal ischemia for $45 \mathrm{~min}$. Renal functions (serum creatinine and BUN), pancreatic functions (serum amylase, lipase and insulin) and fasting blood glucose were measured at 2 h, 1 day, 3 days and 7 days after ischemia. Also, pancreatic histology and malondialdehyde (MDA), catalase and reduced glutathione (GSH) were examined at $2 \mathrm{~h}$ and 7 days after ischemia. The ischemic rats showed significant increase in serum creatinine and BUN with significant increase in serum amylase and lipase at $2 \mathrm{~h}, 1$ day and 3 days after ischemia. Blood glucose and fasting insulin showed no significant change apart from significant increase in insulin in sham group at 1 day after ischemia. Pancreas isolated from ischemic rats showed significant increase in histopathological damage score and significant increase in MDA and catalase enzyme with decrease in GSH. In conclusion, bilateral renal ischemia for 45 min caused significant impairment of pancreatic functions and histology. This might be due to deficiency of antioxidant and increased lipid peroxidations in pancreatic tissues.
\end{abstract}

\section{Key words}

Renal • Ischemia • Reperfusion • Pancreas • Oxidative Stress

\section{Corresponding author \\ Abdel-Aziz M. Hussein, Department of Physiology, Mansoura Faculty of Medicine, Mansoura, Egypt. Fax: +20502248203. E-mail: zizomenna28@yahoo.com}

\section{Introduction}

Renal ischemia/reperfusion injury ( $\mathrm{I} / \mathrm{R})$ is an inevitable consequence of kidney transplantation and after local renal hypoperfusion following partial nephrectomy, renal vascular surgery and aortic crossclamping (Weight et al. 2001). Ischemia/reperfusion injury is a complex phenomenon that induces cell damage through a bi-phasic process. Ischemia initiates the injury by deprivation of the energy needed to maintain ionic gradients and homeostasis, which may ultimately lead to cellular dysfunction and death. Reperfusion exacerbates this damage triggering an inflammatory reaction in which participate free radicals, endothelial factors and leukocytes (Devarajan 2006). Reactive oxygen species (ROS) play an important role in mediating cell damage during I/R injury (Noiri et al. 2001) and I/R inducedtissue injury is caused by an imbalance between production of ROS and antioxidant capacity (Erdogan et al. 2006).

Renal ischemia/reperfusion (I/R) elicits tissue damage in a number of organs: heart, lung and liver (Serteser et al. 2002, Kelly 2003, Yildirim et al. 2003, Gulec et al. 2008). In the liver, it has been demonstrated that renal I/R injury might cause liver oxidative stress and increase lipid peroxidation in liver tissue (Yildirim et al. 
2003, Vaghasiya et al. 2010). Moreover, Kadkhodaee et al. (2009), recently, demonstrated significant decrease in liver GSH, as well as a significant increase in proinflammatory cytokines e.g. TNF- $\alpha$ and antiinflammatory cytokines e.g. IL-10 concentrations in liver after renal $I / R$ injury. In lungs, the role of proinflammatory and proapoptotic factors such as leukocyte trafficking, cytokines/chemokines, activation of caspases, oxidative stress and uremic toxins in lung injury secondary to renal $\mathrm{I} / \mathrm{R}$ injury have been demonstrated (White et al. 2011). In the heart, cardiac myocyte apoptosis and neutrophil infiltration are two of the most important contributors to the pathophysiology of myocardial infarction during renal I/R injury (White et al. 2011). In the pancreas, although, a recent in vitro study demonstrated impairment of kidney function by pancreatic I/R injury through xanthine oxidase enzyme (Khoury et al. 2010), there is no study, up to the best of our knowledge, investigated the impact of renal I/R injury on pancreatic function and histology. So, the aim of this study was to investigate the impact of renal I/R injury on the markers of pancreatic function and histology of pancreas as well as on the oxidative stress state in pancreas.

\section{Materials and Methods}

\section{Experimental animals}

This study was conducted on 24 adult male healthy Sprague Dawley rats weighing between 200$250 \mathrm{~g}$ aging 4-6 months. Animals were bred and housed in the animal house of the Medical Experimental Research center (MERC), Mansoura University, at a temperature of $20^{\circ} \mathrm{C}$, fed a standard laboratory chow and had a free access to tap water. All experimental protocols were approved by our local ethics committee.

\section{Experimental design}

Rats were allocated into 2 groups (12 rats each): Group I (sham); rats were subjected to midline laparotomy and dissection of renal pedicles without any renal ischemia. Group II (ischemic); rats were subjected to all experimental procedure with renal ischemia.

\section{Renal I/R injury model}

The anesthesia was induced by placing rats for $30 \mathrm{~s}$ in a glass container containing a piece of cotton soaked with $10 \mathrm{ml}$ of halothane. Then animals were maintained on sodium thiopental at a dose of
$12 \mathrm{mg} / 100 \mathrm{~g}$ body weight injected intraperitoneally. Under anesthesia, the animal was fixed in the supine position on a thermoregulated heating board to maintain body temperature at $37^{\circ} \mathrm{C}$. A midline laparotomy was done, then both renal pedicles were exposed and clamped for $45 \mathrm{~min}$ using a vascular Bulldog clamp. Blood samples were collected at $2 \mathrm{~h}$ and at day 1 , day 3 and day 7 after ischemia. Pancreatic tissues were collected $2 \mathrm{~h}$ after reperfusion from half of animals (6 rats), and at day 7 from the other half (6 rats) and prepared for histopathological examinations and measurement of markers of oxidative stress.

\section{Biochemical assay}

Serum creatinine and BUN, serum amylase, lipase, fasting insulin and fasting blood glucose were measured at $2 \mathrm{~h}$, day 1,3 and 7 after ischemia. All of these measurements were done by commercially available kits (Fortress diagnostics, UK).

\section{Histological procedures}

After formalin fixation (10\% phosphatebuffered) and dehydration, paraffin-embedded pancreatic sections $(4 \mu \mathrm{m})$ were stained by hematoxylin and eosin. Histopathology for all tissues was evaluated per section in at least 10 randomly selected nonoverlapping fields at $\times 400$ magnifications of the sections. Pancreatic sections were evaluated for the presence of congestion, cellular degenerative changes, cytoplasmic vacuolization and leukocyte infiltration. The histological grading of edema was made using a scale ranging from 0 to $3(0=$ no edema, $1=$ interlobular edema, $2=$ interlobular and moderate intralobular edema, and $3=$ interlobular edema and severe intralobular edema). Leukocytic infiltration was also graded from 0 to $3(0=$ absent, $1=$ scarce perivascular infiltration, $2=$ moderate perivascular and scarce diffuse infiltration, $3=$ abundant diffuse infiltration). Grading of vacuolization was based on the appropriate percentage of acinar cells involved: $0=$ absent, $1=$ less than $25 \%, 2=25-50 \%$ and $3=$ more than $50 \%$ of acinar cells. Hemorrhage was graded: $0=$ no hemorrhage, $1=1-2$ hemorrhagic foci per specimen (slide), $2=3-5$ hemorrhagic foci per slide, $3=$ more than 5 hemorrhagic foci per slide. Necrosis was graded: $0=$ no necrosis, $1=$ less than $15 \%$ of pancreatic cells involved, $2=15-35 \%$ of cells involved, $3=$ more than $35 \%$ of cells involved (Warzecha et al. 2004). 
Table 1. Effect of 45 min bilateral renal ischemia on renal functions, pancreatic functions and blood glucose.

\begin{tabular}{|c|c|c|c|c|c|}
\hline & Group & $2 \mathrm{~h}$ & 1 day & 3 days & 7 days \\
\hline \multicolumn{6}{|l|}{ Renal functions } \\
\hline \multirow{2}{*}{$\begin{array}{l}\text { Serum creatinine } \\
(\mu \mathrm{mol} / \mathrm{l})\end{array}$} & Sham group & $36.24 \pm 4.42$ & $68.07 \pm 10.61$ & $44.20 \pm 4.20$ & $38.89 \pm 0.88$ \\
\hline & Ischemic group & $72.49 \pm 6.19^{*}$ & $93.70 \pm 13.26^{*}$ & $138.79 \pm 10.61^{*}$ & $58.34 \pm 13.26$ \\
\hline \multirow[t]{2}{*}{ Serum BUN (mmol/l) } & Sham group & $7.09 \pm 0.68$ & $12.48 \pm 2.39$ & $16.65 \pm 0.59$ & $8.6 \pm 1.15$ \\
\hline & Ischemic group & $17.42 \pm 1.53^{*}$ & $48.39 \pm 6.59^{*}$ & $37.41 \pm 3.18^{*}$ & $10.59 \pm 1.54$ \\
\hline \multicolumn{6}{|l|}{ Pancreatic functions } \\
\hline \multirow[t]{2}{*}{ Serum amylase (U/l) } & Sham group & $264.0 \pm 44.43$ & $255.0 \pm 22.53$ & $249.17 \pm 33.06$ & $383.67 \pm 40.82$ \\
\hline & Ischemic group & $287.67 \pm 44.68$ & $315.83 \pm 62.26^{*}$ & $498.33 \pm 103.84 *$ & $459.5 \pm 54.38$ \\
\hline \multirow[t]{2}{*}{ Serum lipase (U/l) } & Sham group & $32.00 \pm 5.51$ & $18.67 \pm 6.47$ & $24.0 \pm 9.18$ & $29.83 \pm 10.05$ \\
\hline & Ischemic group & $36.00 \pm 8.03$ & $54.67 \pm 12.25^{*}$ & $74.83 \pm 5.56^{*}$ & $42.33 \pm 15.38$ \\
\hline \multirow{2}{*}{$\begin{array}{l}\text { Fasting insulin } \\
(\mathrm{pmol} / \mathrm{l})\end{array}$} & Sham group & $66.74 \pm 9.79$ & $93.76 \pm 19.79$ & $60.60 \pm 4.03$ & $68.62 \pm 8.26$ \\
\hline & Ischemic group & $46.39 \pm 11.67$ & $57.29 \pm 9.45^{*}$ & $58.38 \pm 12.29$ & $55.21 \pm 8.75$ \\
\hline \multirow{2}{*}{$\begin{array}{l}\text { Fasting blood } \\
\text { glucose (mmol/l) }\end{array}$} & Sham group & $5.84 \pm 0.75$ & $6.97 \pm 0.44$ & $6.09 \pm 0.44$ & $6.05 \pm 0.25$ \\
\hline & Ischemic group & $6.45 \pm 1.57$ & $6.86 \pm 1.13$ & $7.18 \pm 1.43$ & $5.51 \pm 0.49$ \\
\hline
\end{tabular}

All data expressed as Mean \pm SD. Independent T-test. * significant vs. sham group $(p<0.05)$. BUN $=$ blood urea nitrogen

Estimation of lipid peroxidation and antioxidant enzymes in pancreatic tissues

Pancreas tissues, harvested at $2 \mathrm{~h}$ and 7 days after ischemia, were kept in cold conditions (precooled in Petri dish inverted on ice). It was cross-chopped with surgical scalpel into fine slices in chilled $0.25 \mathrm{M}$ sucrose and quickly blotted on a filter paper. The tissue was minced and homogenized in $10 \mathrm{mM}$ Tris- $\mathrm{HCl}$ buffer, $\mathrm{pH} 7.4$ (10\% w/v), with 25 strokes of tight Teflon pestle of glass homogenizer at a speed of $2500 \mathrm{rpm}$. The clear supernatant was used for assays of lipid peroxidation (MDA content) and endogenous antioxidant enzyme catalase (CAT), and reduced glutathione (GSH) by using colorimetric kit (BioDiagnostics, Dokki, Giza, Egypt) according to manufacturer's instructions commercially available kits.

\section{Statistical analysis}

The results are given as mean $\pm \mathrm{SD}$. Independent $\mathrm{T}$ test was used to find statistical difference between sham and ischemic group. The null hypothesis was rejected at the 0.05 level of significance. SPSS 14.0 software was used for data analysis.

\section{Results}

Effects of 45 min bilateral renal ischemia on renal functions (serum creatinine and BUN)

Table 1 shows the results of serum creatinine and BUN in sham and ischemic groups at $2 \mathrm{~h}$, day 1 , day 3 and day 7 after ischemia. Compared to sham group, serum creatinine and BUN were significantly high in ischemic group at $2 \mathrm{~h}$, day 1 , and day 3 only after ischemia $(p<0.05)$. At day 7 there was no significant difference between sham and ischemic group.

Effects of 45 min bilateral renal ischemia on pancreatic functions (serum amylase, lipase, fasting insulin) and fasting blood glucose

Compared to sham group, serum amylase showed significant increase in ischemic group at $2 \mathrm{~h}$, day 1 and day 3 after ischemia $(p<0.05)$, while serum lipase showed significant increase in control group only at days 1 and 3 (Table 1). Compared to sham group, fasting insulin showed significant decrease in ischemic group only at day $1(\mathrm{p}<0.001)$. Fasting blood glucose showed no statistically significant difference between sham and ischemic groups at different periods of follow up (Table 1).

Effect of 45 min bilateral renal ischemia on oxidative stress markers and antioxidants in pancreatic tissues

The results of the MDA, catalase and GSH analyses are shown in Figure 1. Compared to sham group, the level of MDA was significantly high in the pancreatic tissue of the ischemic group at $2 \mathrm{~h}$, but not at 7 days (Fig. 1A). Also, pancreatic catalase level was 

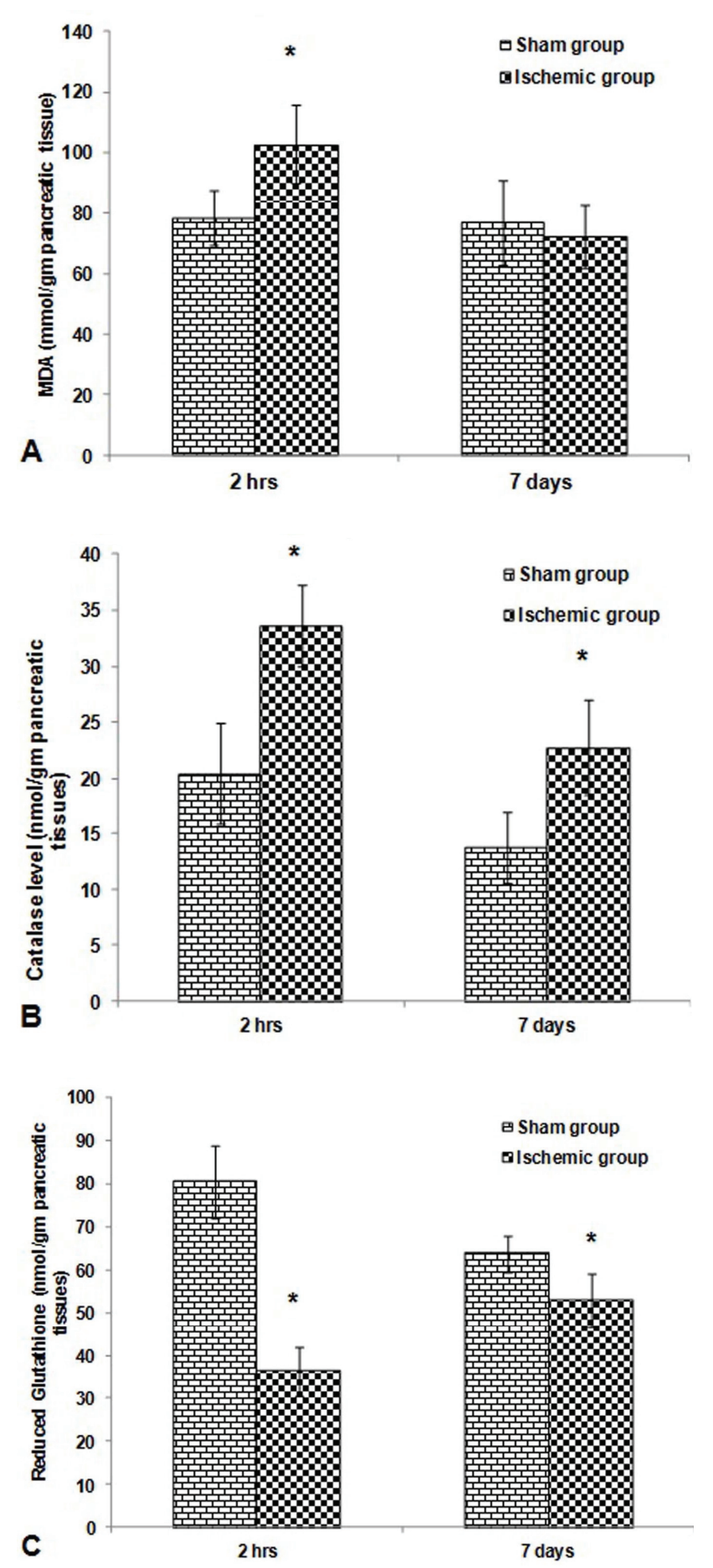

Fig. 1. Effect of 45 min bilateral renal ischemia on pancreatic oxidative stress MDA (A), Catalase (B), and reduced glutathione (GSH) (C). All data expressed as Mean \pm SD. Independent Ttest. $*$ significant vs. sham group $(p \leq 0.05)$

significantly high in ischemic group when compared with that of sham group at $2 \mathrm{~h}$ and 7 days after ischemia (Fig. 1B). Lastly, compared to sham group, GSH concentration in pancreatic tissues was significantly low in ischemic group at $2 \mathrm{~h}$ but not at 7 days (Fig. 1C).
Effect of renal ischemia on the weight and histopathology of pancreas

Table 2 shows the results of pancreatic weight and damage score. Compared to sham group, the weight of pancreas was significantly increased in ischemic group at $2 \mathrm{~h}$ after ischemia and at the end of experiment. Also, compared to sham group, pancreatic edema, leucocytic infiltration, and vacuolization were significantly high in ischemic group at $2 \mathrm{~h}$ after ischemia and at the end of the experiment. However, pancreatic necrosis was present only in control ischemic group at $2 \mathrm{~h}$ after ischemia, as well as both groups showed no pancreatic hemorrhage. Figures 2, 3, 4, and 5 are samples of ischemic group.

\section{Discussion}

The main findings of the present study include that, renal $I / R$ injury resulted in a) significant elevation in markers of pancreatic function such as serum amylase and lipase, b) significant elevation of pancreatic damage score, c) significant elevation of pancreatic oxidative stress state. To the best of our knowledge, this is the first study that addressed the effect of renal $\mathrm{I} / \mathrm{R}$ injury on pancreatic function and morphology. Most of research in renal $I / R$ injury has focused on the local renal response to this injury (Kadkhodaee et al. 1996, Hussein et al. 2011). However, recent studies emerged to investigate the remote effects of renal $\mathrm{I} / \mathrm{R}$ injury on distant organs such as liver, brain and lungs (Serteser et al. 2002, Kelly 2003, Yildirim et al. 2003, Gulec et al. 2008). Moreover, Johnson and Nabseth (1970) reported occurrence of pancreatitis in patients with renal transplantation by $2 \%$ and half of these cases were fatal. They attributed this pancreatitis to immunosuppressive drugs, hyperparathyroidism, surgical traumatic pancreatitis and immunologic considerations. So, in the present study, we examined the effect of renal $I / R$ injury on pancreatic functions and histology, as well as on pancreatic oxidative stress status.

In the present study, we showed that $45 \mathrm{~min}$ bilateral renal ischemia caused significant elevation of serum amylase and lipase after the different time intervals. These findings indicate renal $\mathrm{I} / \mathrm{R}$ injury may result in impairment of pancreatic exocrine functions. In agreement with our study, Warzecha et al. (2008) demonstrated, in a rat model of pancreatic I/R injury, that renal not direct ischemic preconditioning caused more elevation in serum amylase and lipase at 12-24 $\mathrm{h}$ after reperfusion. This effect seems to be related to the mechanism of blood flow regulation of the gut. Ischemic 
Table 2. Effects of $45 \mathrm{~min}$ bilateral renal ischemia on pancreatic weight and histopathological damage score.

\begin{tabular}{lllccccc}
\hline \multicolumn{1}{c}{ Group } & $\begin{array}{c}\text { Weight } \\
\text { (mg) }\end{array}$ & Oedema & $\begin{array}{c}\text { Leucocytic } \\
\text { infiltration }\end{array}$ & Vacuolization & Necrosis & Hemorrhage \\
\hline $2 h$ & Sham group & $98.80 \pm 29.40$ & $0-1$ & $0-1$ & 0 & 0 & 0 \\
7 days & Ischemic group & $120.50 \pm 30.31^{*}$ & $1-2^{*}$ & $1-2^{*}$ & $0-1^{*}$ & $0-1^{*}$ & 0 \\
& Sham group & $120.17 \pm 81.55$ & $0-1$ & $0-1$ & 0 & 0 & 0 \\
& Ischemic group & $174.00 \pm 56.39^{*}$ & $1-2^{*}$ & $1-2^{*}$ & $1-2^{*}$ & 0 & 0 \\
\hline
\end{tabular}

Data of pancreatic weight are expressed as Mean \pm SD. Independent T-test. * significant vs. sham group $(p<0.05)$. Numbers representing the predominant grading of pancreatic damage

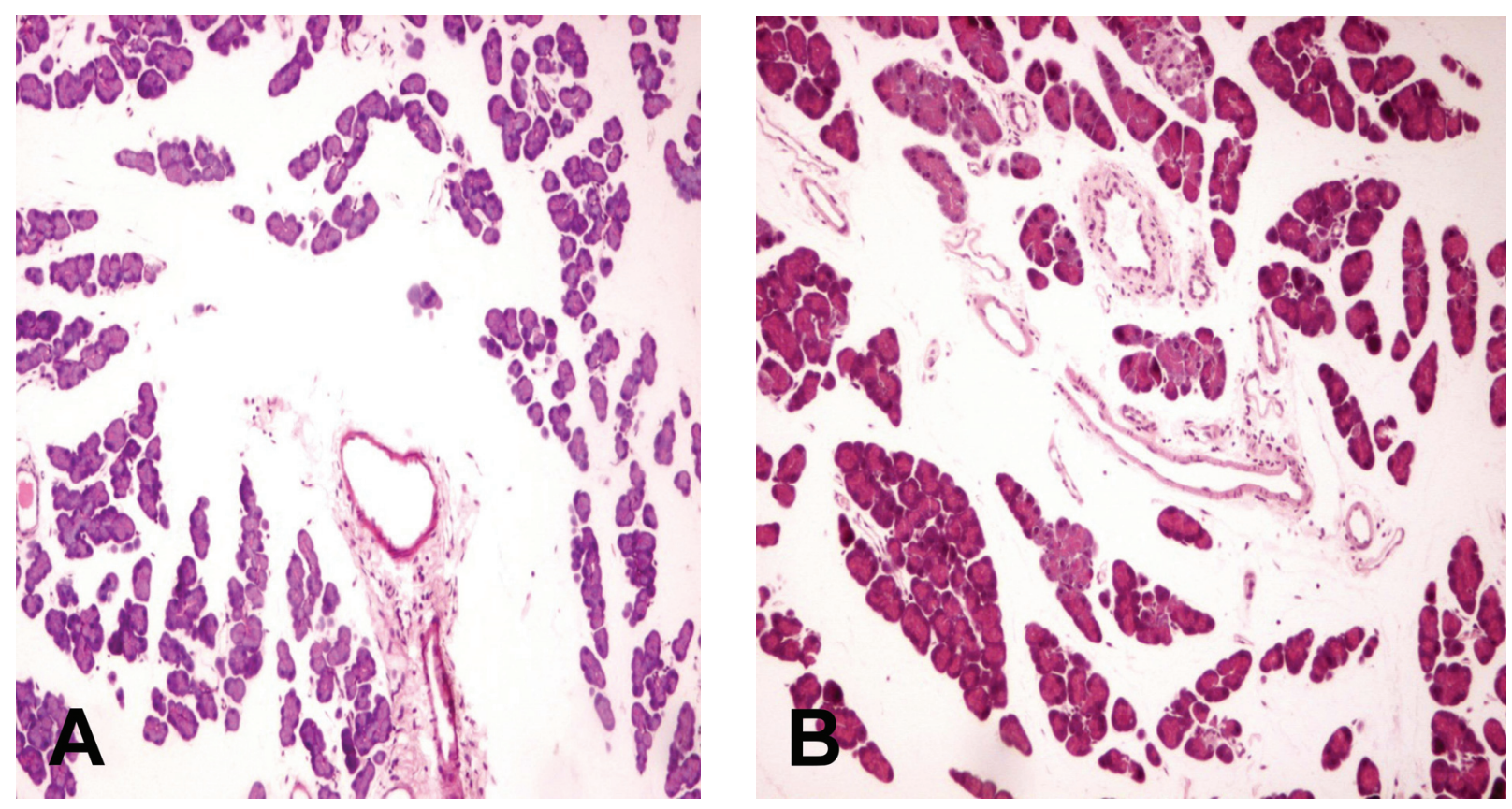

Fig. 2. Edema expanding the interstitial tissue separating pancreatic acini and lobules in ischemic group (A and B) (H \& E, X400).
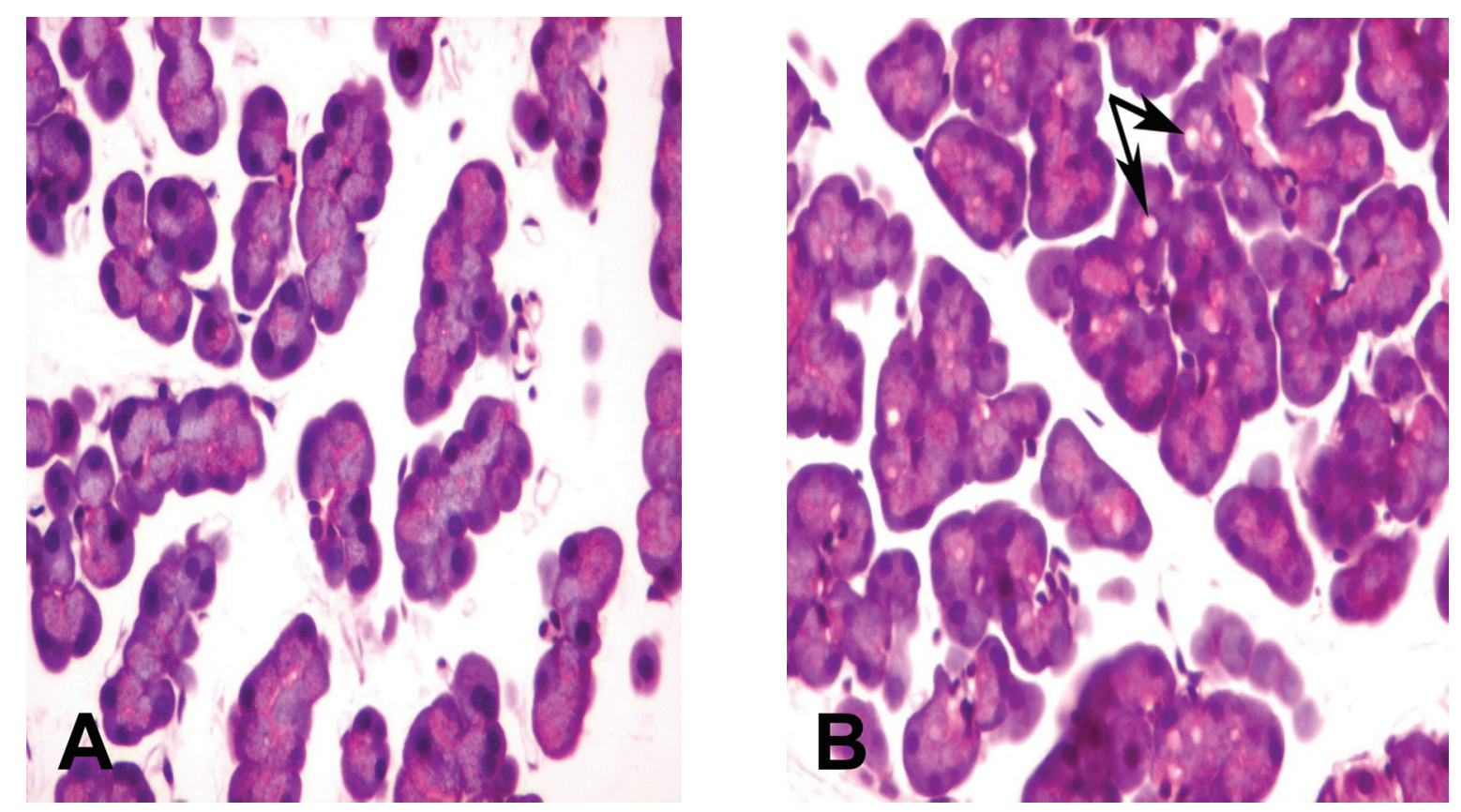

Fig. 3. Pancreatic acinar cell vacuolization (A), vacuoles appear as unstained holes within cytoplasm (arrows) (B) (ischemic group) (H \& E, X400). 

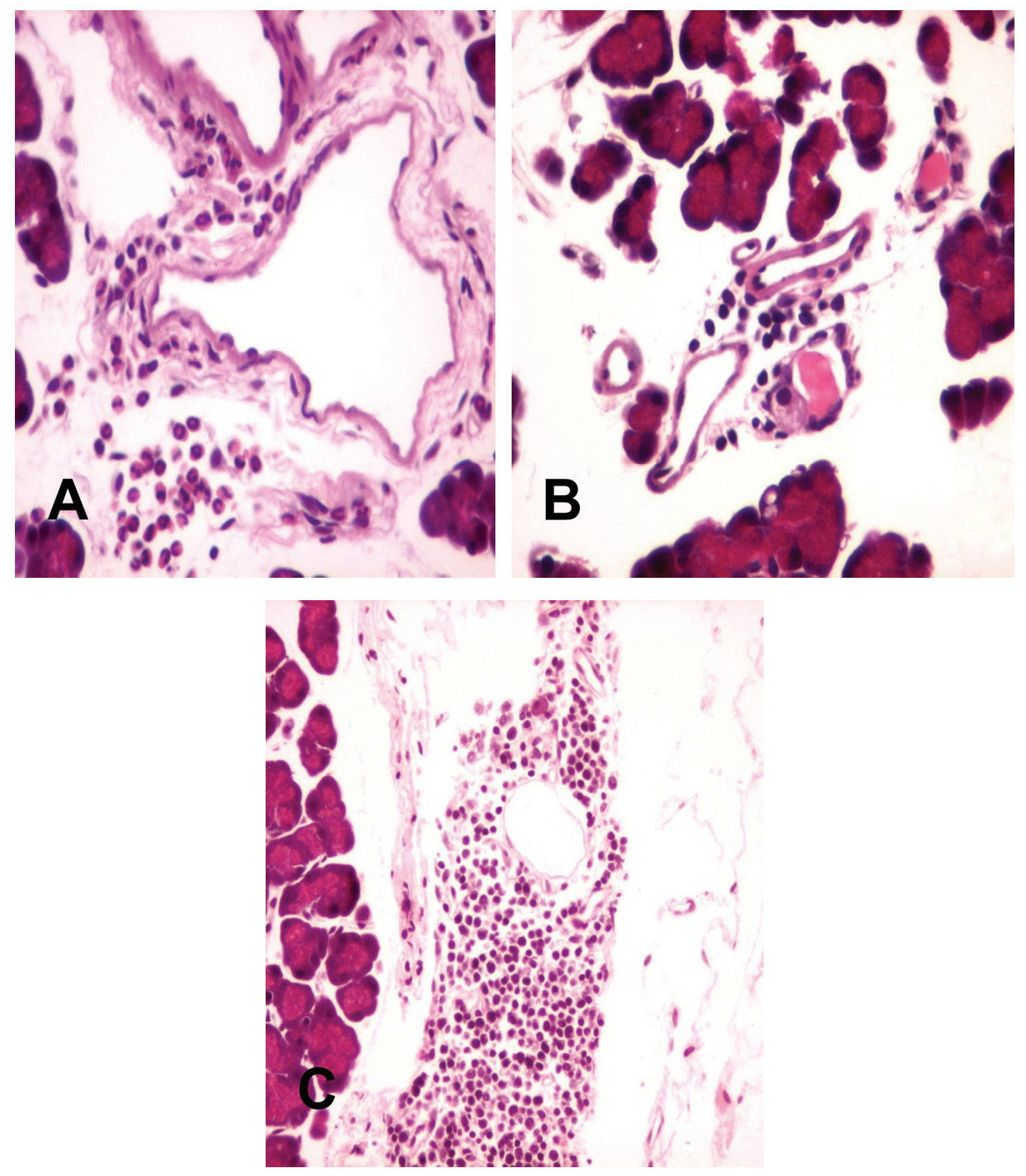

Fig. 4. Mild perivascular inflammatory infiltrate formed mainly of neutrophils (H\&E) (A), mild dense perivascular inflammatory infiltrate (B) ( $H$ \& E, X400), and moderately dense perivascular infiltrate (C) (ischemic group), ( $\&$ \&,$X 400)$.

preconditioning of the kidney is a kind of trauma that results in centrally integrated autonomic mediated cardiovascular response that are designated to increase heart rate, systemic vascular resistance and maintain the arterial blood pressure to vital organs at the expense of gut and skeletal muscle blood flow (Muir 2006). This effect is probably intensified by activation of renin angiotensin system by renal ischemia. This speculation was supported the data reported by Warzecha et al. (2008) who demonstrated reduction of pancreatic blood flow between $6 \mathrm{~h}$ to $24 \mathrm{~h}$ by renal ischemic preconditioning. However, this point was not investigated in our study. On the other hand, fasting insulin showed no significant change in ischemic rats when compared to sham group apart from significant decrease in day 1 . Moreover, fasting blood glucose showed no the endocrine functions of pancreas. These findings suggested that the pancreatic injury induced by renal ischemia was not sufficient to affect the endocrine functions of pancreas or to affect glucose homeostasis. Further studies are needed to assess the functions of $\beta$ cells of islets of Langerhans and its histology. 


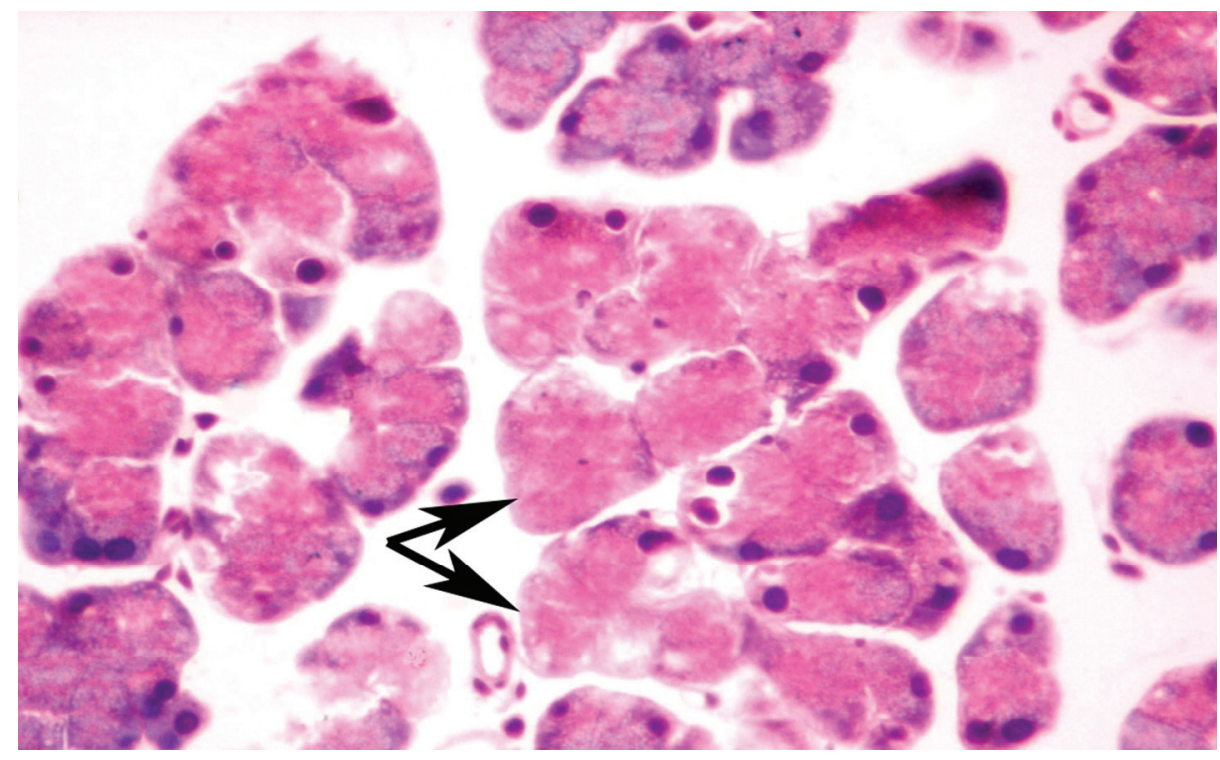

Fig. 5. Groups of necrotic acinar cells (arrows) (ischemic group), ( $\mathrm{H}$ \& $E, X 400)$.

Oxidative stress injury of the kidney may play a major role in inducing remote organ injury. The involvement of ROS in I/R injury to the kidney and other organs is widely accepted. We examined oxidative stress state in pancreas during renal $\mathrm{I} / \mathrm{R}$ injury. We found significant increase in concentration of MDA (marker of lipid peroxidation), and catalase enzyme and significant decrease in GSH in pancreatic tissues after renal $\mathrm{I} / \mathrm{R}$ injury. These findings suggest increased oxidative stress in pancreas during renal $\mathrm{I} / \mathrm{R}$ injury. In consistence with these findings Kadkhodaee et al. (2009) demonstrated significant reduction of hepatic level of GSH with different periods of renal ischemia. Moreover, Khoury et al. (2010) demonstrated that the ROS, generated in the ischemic pancreas, could be associated with edema in the vasculatures of both ischemic-nontreated and ischemictreated pancreases and the exposed kidneys (Weinbroum et al. 2001). The hyperamylasemia and hyperlipasemia could be explained by pancreatic injury caused by ROS. This is evidenced in the present study by significant increase in MDA (marker of lipid peroxidation) and GSH (marker of endogenous antioxidant) in ischemic rats. Tamura et al. (1993) suggested that the active oxygen species that are generated by short-term pancreatic ischemia and reperfusion injure the endothelium and cause hyperamylasemia. Also, Junior et al. (2010) demonstrated that pancreatic $\mathrm{I} / \mathrm{R}$ injury produced hyperamylasemia probably due to ROS damage.

The histological examination of pancreas revealed edema, leucocytic infiltration, and vacuolization in ischemic group at $2 \mathrm{~h}$ after ischemia and at the end of the experiment and pancreatic necrosis in ischemic group at $2 \mathrm{~h}$ after ischemia, but, there was no pancreatic hemorrhage. So, these pathological findings indicate that bilateral renal ischemia for $45 \mathrm{~min}$ cause acute inflammatory reaction in pancreas. This inflammatory reaction may be similar to that observed in liver, heart and lung in previous studies (Serteser et al. 2002, Jeyarajah et al. 2003, Kadkhodaee et al. 2009). Some studies demonstrated significant increase in proinflammatory cytokines TNF- $\alpha$ and IL-10 concentrations in liver after renal $\mathrm{I} / \mathrm{R}$ injury (Serteser et al. 2002, Jeyarajah et al. 2003, Kadkhodaee et al. 2009). Serteser et al. (2002) have suggested that $30 \mathrm{~min}$ ischemia and $60 \mathrm{~min}$ reperfusion is sufficient to elicit remote effects of I/R injury. In the present study $2 \mathrm{~h}$ reperfusion is sufficient to elicit the remote effects of renal I/R injury on pancreas. Also, Warzecha et al. (2008) demonstrated significant elevation in serum IL1 $\beta$ in a model of pancreatic $\mathrm{I} / \mathrm{R}$ injury by renal ischemic preconditioning with maximal rise $6 \mathrm{~h}$ after reperfusion. Moreover, White et al. (2011) demonstrated the involvement of proinflammatory and proapoptotic factors such as leukocyte trafficking, cytokines/chemokines, and activation of caspases in pulmonary injury induced by renal I/R injury.

\section{Conclusion}

We conclude that 45 min bilateral renal ischemia causes detrimental changes in pancreatic exocrine functions and morphology as well as it enhances oxidative stress and inflammatory states in pancreas. We recommend, care should be taken to protect other organs such as pancreas remote from I/R sites, especially during renal surgery. 


\section{Conflict of Interest}

There is no conflict of interest.

\section{Acknowledgements}

This work was funded by Medical Research Experimental Center, Mansoura Faculty of Medicine, Mansoura, Egypt, Student Summer Grant \# 10.

\section{References}

CERANOWICZ P, WARZECHA Z, DEMBINSKI A, BILSKI J, PAWLIK WW, SENDUR R, JAWOREK J, KONTUREK SJ, TOMASZEWSKA R, STACHURA J: Immunohistochemical detection of expression of PDGF, FGF-2, VEGF and TGFß RII in the pancreas during pancreatic regeneration after ischemia/reperfusioninduced pancreatitis. Molecular and physiological aspects of regulatory processes of the organism. 12th International Symposium of Polish Network of Molecular and Cellular Biology UNESCO/PAS. Cracow, June 5-6, 2003, pp 74-75.

DEVARAJAN P: Update on mechanisms of ischemic acute kidney injury. J Am Soc Nephrol 17: 1503-1520, 2006.

ERDOGAN H, FADILLIOGLU E, YAGMURCA M, UCAR M, IRMAK K: Protein oxidation and lipid peroxidation after renal ischemia-reperfusion injury: protective effects of erdosteine and N-acetylcysteine. Urol Res 34: 4146, 2006.

GULEC B, COSKUN K, YIGITLER T, YIGIT T, AYDIN A, ONER K: Ischemia-reperfusion injury in the liver during renal transplantation: does perfusion solution play any role? Transplant Proc 40: 59-62, 2008.

HUSSEIN AA, SHOKEIR AA, SARHAN ME, EL-MENBAWY FR, ABD-ELMONEIM HA, EL-NASHAR EM, BARAKAT NM: Effects of combined erythropoietin and epidermal growth factor on renal ischaemia/reperfusion injury: a randomized experimental controlled study. BJU Int 107: 323-328, 2011.

JEYARAJAH DR, KIELAR ML, ZHOU XJ, ZHANG Y, LU CY: Acute bile duct ligation ameliorates ischemic renal failure. Nephron Physiol 95: p28-p35, 2003.

JOHNSON WC, NABSETH DC: Pancreatitis in renal transplantation. Ann Surg 171: 309-314, 1970.

JUNIOR RFM, KUBRUSLY MS, BELLODI-PRIVAT M, MOLAN NAT, MACHADO MCC, D'ALBUQUERQUE LAC: Beneficial effects of $\mathrm{N}$-acetyl cysteine on pancreas and kidney following experimental pancreatic ischemia-reperfusion in rats. Clinics 65: 311-316, 2010.

KADKHODAEE M, HANSON GR, TOWNER RA, ENDRE ZH: Detection of hydroxyl and carbon-centred radicals by EPR spectroscopy after ischaemia and reperfusion of the rat kidney. Free Radic Res 25: 31-42, 1996.

KADKHODAEE M, GOLAB F, ZAHMATKESH M, GHAZNAVI R, HEDAYATI M, ARAB HA, OSTAD SN, SOLEIMANI M: Effects of different periods of renal ischemia on liver as a remote organ. World $J$ Gastroenterol 15: 1113-1118, 2009.

KELLY KJ: Distant effects of experimental renal ischemia/reperfusion injury. Am J Nephrol 14: 1549-1558, 2003.

KHOURY W, NAMNESNIKOV M, FEDOROV D, ABU-GAZALA S, WEINBROUM AA: Mannitol attenuates kidney damage induced by xanthine oxidase-associated pancreas ischemia-reperfusion. J Surg Res 160: 163$168,2010$.

MUIR W: Trauma: physiology, pathophysiology, and clinical implications. J Vet Emerg Crit Care 16: 253-263, 2006.

NOIRI E, NAKAO A, UCHIDA K, TSUKAHARA H, OHNO M, FUJITA T, BRODSKY S, GOLIGORSKY MS: Oxidative and nitrosative stress in acute renal ischemia. Am J Physiol 281: F948-F957, 2001.

SERTESER M, KOKEN T, KAHRAMAN A, YILMAZ K, AKBULUT G, DILEK ON: Changes in hepatic TNF- $\alpha$ levels, antioxidant status, and oxidation products after renal ischemia/reperfusion injury in mice. $J$ Surg Res 107: 234-240, 2002.

TAMURA K, MANABE T, KYOGOKU T, ANDOH K, OHSHIO G, TOBE T: Effect of postischemic reperfusion on the pancreas. Hepatogastroenterology 40: 452-456, 1993.

VAGHASIYA JD, SHETH NR, BHALODIA YS, JIVANI NP: Exaggerated liver injury induced by renal ischemia reperfusion in diabetes: effect of exenatide. Saudi J Gastroenterol 16: 174-180, 2010. 
WARZECHA Z, DEMBINSKI A, CERANOWICZ P, DEMBINSKI M, KOWNACKI P, KONTUREK SJ, TOMASZEWSKA R, STACHURA J, HLADKI W, PAWLIK WW: Immunohistochemical expression of FGF-2, PDGF-A, VEGF and TGF $\beta$ RII in the pancreas in the course of ischemia/reperfusion-induced acute pancreatitis. J Physiol Pharmacol 55: 791-810, 2004.

WARZECHA Z, DEMBINSKI A, CERANOWICZ P, CIESZKOWSKI J, KONTUREK SJ, DEMBINSKI M, KUSNIERZ-CABALA B, TOMASZEWSKA R., PAWLIK WW: Ischemic preconditioning of the hindlimb or kidney does not attenuate the severity of acute ischemia/reperfusion-induced pancreatitis in rats. $J$ Physiol Pharmacol 59: 337-352, 2008.

WEIGHT SC, WALLER JR, BRADLEY V, WHITING PH, NICHOLSON ML: Interaction of eicosanoids and nitric oxide in renal reperfusion injury. Transplantation 72: 614-619, 2001.

WEINBROUM AA, KLUGER Y, SHAPIRA I, RUDICK V: Methylene blue abolishes aortal tone impairment induced by liver ischemia-reperfusion in a dose response manner: an isolated-perfused double-organ rat model study. Shock 15: 226-230, 2001.

WHITE LE, CHAUDHARY R, MOORE LJ, MOORE FA, HASSOUN HT: Surgical sepsis and organ crosstalk: the role of the kidney. J Surg Res 167: 306-315, 2011.

YILDIRIM A, GUMUS M, DALGA S, SAHIN YN, AKCAY F: Dehydroepiandrosterone improves hepatic antioxidant systems after renal ischemia-reperfusion injury in rabbits. Ann Clin Lab Sci 33: 459-464, 2003. 